\title{
Relationship between People's Health and the Haze.
}

\author{
Zhu Wang ${ }^{1, a}$ \\ ${ }^{1}$ School of Zhu Wang, North China Electric Power University, Baoding 071000, China; \\ a984628317@qq.com
}

Keywords: AHP method, PM 2.5, mathematic model.

\begin{abstract}
Since 2013, haze has becoming more and more thick in the north area of China. The haze affects our normal life. So we need to find the relationship between the haze and PM 2.5.The task needs us to find data about PM 2.5. We can analyze the relationship between the haze and PM 2.5 with these data. The main method of our modeling is AHP method. We establish model to handle the problem. We discuss the relationship between injury coefficient and PM 2.5's components and cities.
\end{abstract}

\section{Introduction}

There are things floating around in the air. Most of them, you cannot even see. They are a kind of air pollution called particles or particulate matter. In fact, particulate matter may be the air pollutant that most commonly affects people's health. Obviously, the unhealthy degree increases with the rise of concentration of PM 2.5. PM2.5, with aerodynamic diameter less than or equal to 2.5 microns in fine particulate matter, is regarded as the most important pollutants in haze. PM2.5 can through the respiratory tract into the alveoli, causing harm to human health.

\section{AHP method}

\subsection{The basic calculation}

We choose AHP to analyze the relationship between the cities and components of pm 2.5 and harmful degree.AHP can provide a layered model which can divided by target, principle and solution.The target layer is the final result of our model.The principle included the components of pm 2.5.They are the elements which affect the injury coefficient.

The easy will comparative judgment quantitative, introducing $1 \sim 9$ ratio mark degree method, provisions $1,3,5,7,9$, respectively, which indicated that judgment based on experience, compared to the elements of I and elements of J: equally important, slightly important, strong, strong important, absolutely important, and 2, 4, 6, 8 said the compromise between the two judgment level value. Table 1 shows that.

Table 1. The meaning of scales

\begin{tabular}{cc}
\hline scale & meaning (compare factors $\mathrm{i}$ and $\mathrm{j}$ ) \\
\hline 1 & Factors $\mathrm{i}$ and $\mathrm{j}$ are equally important \\
3 & Factors $\mathrm{i}$ and $\mathrm{j}$ are slightly important \\
5 & Factors $\mathrm{i}$ and $\mathrm{j}$ is of great importance \\
7 & Factors $\mathrm{i}$ and $\mathrm{j}$ are strongly important \\
9 & Factors $\mathrm{i}$ and $\mathrm{j}$ is absolutely important \\
2.4 .6 .8 & The intermediate values of two adjacent factors
\end{tabular}

Reciprocal

Factors $\mathrm{i}$ and $\mathrm{j}$ are compared to determine the matrix $\mathrm{i} \mathrm{j}$ a, then the factors $\mathrm{j}$ and $\mathrm{i}$ compared to the judgment of $\mathrm{a}_{\mathrm{ji}}=1 / \mathrm{a}_{\mathrm{ij}}$

(1) $\mathrm{N}$ root mean square of the product of each element of the matrix $A$.

$$
\overline{w_{1}}=\sqrt[n]{\prod_{j=1}^{n} a_{i j}}(i=1,2, \ldots, n)
$$


(2) By using formula (2) (3), we can get $W$ which is the approximate value of the characteristic vector

$$
\begin{gathered}
\mathrm{w}_{\mathrm{i}}=\frac{\overline{\mathrm{w}_{1}}}{\sum_{\mathrm{i}=1}^{\mathrm{n}} \overline{\mathrm{w}_{1}}} \\
\mathrm{~W}=\left(\mathrm{w}_{1}, \mathrm{w}_{2}, \ldots, \mathrm{w}_{\mathrm{n}}\right)^{\mathrm{T}}
\end{gathered}
$$

(3) Finding the maximum eigenvalue of feature vector $W$.

$$
\lambda_{\max }=\frac{1}{\mathrm{n}} \sum_{\mathrm{i}}\left(\frac{(\mathrm{AW})_{\mathrm{i}}}{\mathrm{w}_{\mathrm{i}}}\right)
$$

\subsection{Consistency check}

According to the principle of analytic hierarchy process, the consistency of the difference of $N$ and Max is analyzed by using the theory of $A$. We can use the consistency index $(C I)$ and calculate the consistency ratio $(C R)$ to check the consistency of our model.

$$
\begin{gathered}
\mathrm{CI}=\frac{\lambda_{\max }-\mathrm{n}}{\mathrm{n}-1} \\
\mathrm{CR}=\frac{\mathrm{CI}}{\mathrm{RI}}
\end{gathered}
$$

\section{The practical application}

In this model, we must definite the scale at first. We use the scale to describe the importance of different elements.In this model, we use the scale to describe the relationship between PM 2.5 and its components. Figure 1 shows the steps to use AHP method.

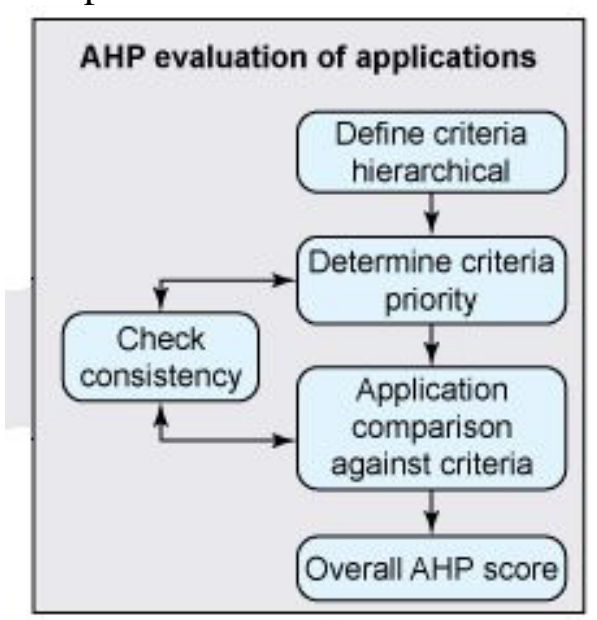

Fig. 1 The steps of $\mathrm{AHP}^{[2]}$

And PM 2.5 includes different kinds of elements such as Pb,Mn,Sb,As,Cd,Co,Cr.....and materials like PAHs. We take some typical elements and materials to approach.We get the concentration of pm 2.5's components by looking at data. This value represents the element density (vg/m3).

Table 2.Content of each element in the air

\begin{tabular}{lccccccccc}
\hline & $\mathrm{Mn}$ & $\mathrm{Sb}$ & $\mathrm{As}$ & $\mathrm{Cd}$ & $\mathrm{Pb}$ & $\mathrm{Co}$ & $\mathrm{Cr}$ & $\mathrm{SO}^{2-}$ & $\mathrm{PAHS}$ \\
\hline Beijing & 0.354 & 0.0028 & 0.023 & 0.012 & 0.481 & 0.0036 & 0.073 & 2.15 & 0.015 \\
Tianjin & 0.013 & 0.0021 & 0.003 & 0.001 & 0.101 & 0.0026 & 0.023 & 1.91 & 0.1492 \\
Qing & & & & & & & & \\
huangdao & 0.134 & 0.001 & 0.007 & 0.001 & 0.237 & 0.0027 & 0.074 & 1.99 & 0.176 \\
Xi'an & 0.325 & 0.0031 & 0.0123 & 0.01825 & 0.2675 & 0.00412 & 0.076 & 2.32 & 0.0128 \\
Lanzhou & 0.144 & 0.0016 & 0.011 & 0.09258 & 0.104 & $3 \times 10^{-6}$ & 0.013 & 1.017 & 0.0009 \\
Yinchuan & 0.183 & 0.0018 & 0.009 & 0.004 & 0.114 & 0.0017 & 0.019 & 1.06 & 0.0073 \\
Urumqi & 0.015 & 0.0007 & 0.009 & 0.00125 & 0.3738 & 0.0012 & 0.039 & 1.34 & 0.042 \\
Anshan & 0.106 & 0.0021 & 0.012 & 0.0106 & 0.1303 & 0.001 & 0.065 & 2.06 & 0.113 \\
Zhengzhou & 0.039 & 0.003 & 0.032 & 0.00549 & 0.3084 & 0.001 & 0.035 & 2.12 & 0.165 \\
\hline
\end{tabular}


We can calculate the final weight and the weight of principles by the matrix.We use the final weight as the standard to evaluate the injury coefficient of different cities.

According to other papers,we get a whole order of importance of PM 2.5's components: $(\mathrm{PAHs}, \mathrm{Pb})>(\mathrm{As}, \mathrm{Cr})>(\mathrm{Cd}, \mathrm{Co})>\left(\mathrm{Mn}, \mathrm{Sb}, \mathrm{SO}_{4}{ }^{2-}\right)$

So we give different scales to them,then we can get a matrix in table 3.

Table 3. Relatively important degree of each element

\begin{tabular}{lccccccccc}
\hline & $\mathrm{Mn}$ & $\mathrm{Sb}$ & $\mathrm{As}$ & $\mathrm{Cd}$ & $\mathrm{Pb}$ & $\mathrm{Co}$ & $\mathrm{Cr}$ & $\mathrm{SO}^{2-}$ & $\mathrm{PAHs}$ \\
\hline $\mathrm{Mn}$ & 1 & $1 / 2$ & $1 / 5$ & $1 / 4$ & $1 / 8$ & $1 / 3$ & $1 / 6$ & 2 & $1 / 7$ \\
$\mathrm{Sb}$ & 2 & 1 & $1 / 4$ & $1 / 3$ & $1 / 5$ & $1 / 2$ & $1 / 5$ & 3 & $1 / 6$ \\
$\mathrm{As}$ & 5 & 4 & 1 & 2 & $1 / 4$ & 3 & $1 / 2$ & 6 & $1 / 3$ \\
$\mathrm{Cd}$ & 4 & 3 & $1 / 2$ & 1 & $1 / 5$ & 2 & $1 / 3$ & 5 & $1 / 4$ \\
$\mathrm{~Pb}$ & 8 & 7 & 4 & 5 & 1 & 6 & 3 & 9 & 2 \\
$\mathrm{Co}$ & 3 & 2 & $1 / 3$ & $1 / 2$ & $1 / 6$ & 1 & $1 / 4$ & 4 & $1 / 5$ \\
$\mathrm{Cr}$ & 6 & 5 & 2 & 3 & $1 / 3$ & 4 & 1 & 7 & $1 / 2$ \\
$\mathrm{SO} 4$ & $1 / 2$ & $1 / 3$ & $1 / 6$ & $1 / 5$ & $1 / 9$ & $1 / 4$ & $1 / 7$ & 1 & $1 / 8$ \\
$\mathrm{PAHs}$ & 7 & 6 & 3 & 4 & $1 / 2$ & 5 & 2 & 8 & 1 \\
\hline
\end{tabular}

Table 4. The values of RI

\begin{tabular}{l|rrrrrrrrr}
\hline $\mathrm{n}$ & 1 & 2 & 3 & 4 & 5 & 6 & 7 & 8 & 9 \\
\hline $\mathrm{RI}$ & 0 & 0 & 0.58 & 0.9 & 1.12 & 1.24 & 1.32 & 1.41 & 1.45 \\
\hline
\end{tabular}

After calculating and using the table 4, the $C R$ of the method is 0.038981702 . It is less than 0.1 . So this method is feasible.

Table 5. The final order of the layers (Cont)

\begin{tabular}{cccccc}
\hline Principles & $\mathrm{Mn}$ & $\mathrm{Sb}$ & $\mathrm{As}$ & $\mathrm{Cd}$ & $\mathrm{Pb}$ \\
\hline Weight of & 0.025 & 0.036 & 0.108 & 0.074 & 0.308 \\
principles & & & & & \\
Beijing & 0.354 & 0.00285 & 0.023 & 0.012 & 0.481 \\
Tianjin & 0.013 & 0.00206 & 0.003 & 0.001 & 0.101 \\
Qinhuangdao & 0.134 & 0.000985 & 0.007 & 0.001 & 0.237 \\
Xi'an & 0.325 & 0.0031 & 0.0123 & 0.01825 & 0.2675 \\
Lanzhou & 0.1443 & 0.00163 & 0.011 & 0.0925 & 0.104 \\
Yinchuan & 0.183 & 0.00183 & 0.009 & 0.004 & 0.114 \\
Urumqi & 0.0148 & 0.00068 & 0.0085 & 0.00125 & 0.3737 \\
Anshan & 0.106 & 0.00206 & 0.012 & 0.0106 & 0.1303 \\
Zhengzhou & 0.039 & 0.00297 & 0.0322 & 0.005489 & 0.30836 \\
\hline & Refer to Table $4($ Continued) & & \\
\hline Principles & Co & Cr & SO4- & PAHs & The final \\
& & & & weight \\
\hline Weight of principles & 0.051 & 0.157 & 0.018 & 0.223 & \\
Beijing & 0.00358 & 0.073 & 2.15 & 0.015 & 0.21366 \\
Tianjin & 0.00259 & 0.023 & 1.91 & 0.1492 & 0.10308 \\
Qinhuangdao & 0.00268 & 0.074 & 1.99 & 0.176 & 0.16372 \\
Xi’an & 0.00412 & 0.076 & 2.32 & 0.0128 & 0.14831 \\
Lanzhou & $3 \times 10^{-6}$ & 0.013 & 1.017 & 0.0009 & 0.06411 \\
Yinchuan & 0.00166 & 0.019 & 1.06 & 0.0073 & 0.06459 \\
Urumqi & 0.00118 & 0.039 & 1.34 & 0.042 & 0.15593 \\
Anshan & 0.001 & 0.065 & 2.06 & 0.113 & 0.11718 \\
Zhengzhou & 0.00099 & 0.035 & 2.12 & 0.165 & 0.18016 \\
\hline
\end{tabular}


From table 5, we can get the conclusion by the data in table 4. The order of urban pollution degree from high to low is Beijing, Zhengzhou, Qinhuangdao, Urumqi, Xi'an, Anshan, Tianjin, Yinchuan and Lanzhou.

\section{Result}

In order to check the accuracy of the model, we use the rate of illness of the city as the standard. We use the standard to evaluate the negative influence. According to data we get, the fact of the urban pollution is Beijing, Zhengzhou, Urumqi, Qinhuangdao, Xi’an, Anshan, Tianjin, Yinchuan and Lanzhou.

By comparison, our model is accurate within the error range.

\section{Conclusion}

PM 2.5's serious impact on ecology, climate and economy has caused many environmental and health effects, which has given rise to the social and widespread public attention. Our model can handle the problem as a system. We can handle it in a more simple way. The amount of data we need is small, so we can put more attention on modeling. The character of our model is that we establish layers in every model, so we can see the relationships between those elements more clearly. By calculating the weight, we can see the element's importance directly. Then we check the accuracy of our models. The accuracy is also satisfying. So we hope our model can help people analyze the problem of PM 2.5

\section{Reference}

[1] Yang Hua Tianjin PM2 5 Distribution and Analysis of Heavy Metals [J] Industrial Safety and Environmental Protection, 2015 (10): 84-86.

[2] http://image.baidu.com/search/detail?ct=503316480\&z=0\&ipn=d\&word=AHP (English flow chart) (in Chinese)

[3] Cui Yanping, Sun Zhihao. An overview of the research on human health effects in PM2. [J]. 5 Environmental Science and technology, 2013, 34 (1): 237-243.

[4] Cao Lizhen, Yan Binfeng. The hazard assessment of typical heavy metal elements in PM 2.5 of Tianjin city [J]. Environmental science and technology, 2008, 43(6): 1246-1248.

[5] Lai Yijian, Lv Sheng, Jin Chengyu, et al. Content and dissolution behavior of heavy metal elements in atmospheric fine particulate matter [J]. Laboratory research and exploration, 2015, 34 (4): 50-52.

[6] Cui Yanping, Sun Zhihao. PM 2.5 on human health impact research overview [J]. Environmental science and technology, 2013, 04:75-78.

[7] Fan Shuxian, fan rice, Yan Peijun, et al. Environmental pollution characteristics of Yinchuan PM2.5 heavy metals analysis [J]. 2006 